\title{
Working with adolescents with mental disorders: the efficacy of a multiprofessional intervention
}

\author{
Gatta Michela ${ }^{1 *}$, Pertile Riccardo ${ }^{2}$, Testa Costantino Paolo ${ }^{3}$, Tomadini Paola ${ }^{1}$, \\ Perakis Ecaterini ${ }^{4}$, Battistella Pier Antonio ${ }^{3}$ \\ ${ }^{1}$ Pediatrics Department, University of Padua, Padua, Italy; *Corresponding Author: michela.gatta@unipd.it \\ ${ }^{2}$ Department of Medicine and Public Health, Section of Psychiatry and Clinical Psychology, University of Verona, Verona, Italy \\ ${ }^{3}$ Neuropsychiatric Unit for Children and Adolescents, ULSS 16, Padua, Italy \\ ${ }^{4}$ Neuropsychiatric Unit for Children and Adolescents, ULSS 9, Treviso, Italy
}

Received 4 March 2010; revised 9 March 2010; accepted 15 March 2010.

\begin{abstract}
The aim of this work was to compare multiprofessional and uniprofessional interventions applied to adolescent patients affected by psychiatric disorders. The initial hypothesis is that a multiprofessional intervention is more efficacy than a single one. A hundred individuals, 66 males and 34 females, aged between 12 and 19 years affected by emotional and behavioural problems, were selected and divided into 5 groups under the therapeutic treatment. Subjects, after diagnosis (ICD 10) and therapeutic suggestion, were clinically followed for 12 months. The Global Assessment Functioning Scale (GAF) was used to evaluate therapeutic efficacy of interventions. The outcome is associated with the type of intervention: who got clinically better are those patients who underwent multiprofessional integrated therapy rather then a single intervention.
\end{abstract}

Keywords: Adolescence; Psychopathology; Interprofessional Intervention; Compliance; Outcome

\section{INTRODUCTION}

The approaches to problems concerning mental health can historically be grouped into three theoretical-methodological systems: the psychological one, the bio-pharmacological one and the socio-environmental one. The operators have often the tendency to ideologically support one the above approaches thus emphasizing a dichotomy which originates from an old separation between body and mind and between individual and setting. According to this trend the therapist with biological education often tends to reduce everything to choosing the appropriate drug to eliminate the symptom. The therapist with psychological education is only interested in giving the patient the most suitable interpretation for putting him in the condition to overcome the symptom; while the educational therapist tends to search for the breakdowns of social nature which are considered the cause of the pathological behaviors, in order to suggest more adequate relational models. Everyone penned in his own shell often mistrusts the other approach running the risk of misunderstanding the patient's needs and of carrying out partial or ineffective interventions.

Many studies scrutinized and compared the benefits of distinct treatment settings for different psychopathologies (psychosis, eating disorder, mood disorder, behavioural problems, ADHD, etc) and reviewed the different treatment modalities that have proven helpful in the management of young patients [1-5]. Although different treatment settings, a multi-modal treatment approach comprising individual psychotherapy, pharmacology and family-based interventions are emphasised and recommended, nevertheless, evidence-based findings on the effect of different treatment methods are limited [6-9].

\section{AIM}

This work evaluates different ways of approaching adolescents with mental disorders. Its aim is that of comparing multiprofessional interventions with interventions based on a single approach and analyzing their therapeutic efficacy. The initial hypothesis is that a multiprofessional intervention is more efficient than an intervention based on a single approach. Moreover the authors want to study the influence that linkage variables such as psychiatric diagnosis, timing of intervention, therapeutic compliance, patients' participation, have with different types of treatments (educational, psychological and psy- 
chiatric ones) and different associations of treatments.

\section{METHODOLOGY AND SAMPLE}

The Neuropsychiatric Unit the patients were referred to, is a second level service which treats medium-severe psychopathological disorders. The structure provides for services characterized by different types of interventions (psychodynamic oriented psychotherapy, educational treatment, pharmacological therapy) chosen according both to the judgment of the specialist who visit the patient and to the service's vacancy at that moment. To verify the efficacy of different treatments, it has run a retrospective study which has analysed those treated patients for whom one year follow up was available. Patients consecutively undergone one of the three treatments (single or in association) during a six months period were 112 individuals. The period is not very long to limit the unhomogeneity of the sample. One year follow up was available for 100 out of 112 subjects.

The psychiatric disorders of the subjects were diagnosed according to ICD 10 [10]. After diagnosis, patients were suggested to undergo therapeutic treatment, on the basis of the understanding and written consent of each subject and his/her parents. Three kinds of treatment were applied: psychological one (psychotherapy with interviews once a week or twice a month, with psychodynamic orientation), psychiatric one (pharmacotherapy antidepressant or atypical antipsychotic drugs and clinical monitoring with one to three psychiatric visits every three months) and educational one (various activities such as theatre/expressive-painting/motility in team and manual laboratories, mediated by educational operators, where the patient can experience his/her abilities and limits individually or in group). These interventions were adopted singularly or in association (two or three of them). Patients were tested before and after the treatment. The Global Assessment Functioning Scale (GAF) [11,12] and Youth Self Report (YSR 11-18) [13-15] were used to evaluate therapeutic efficacy of interventions 12 months after the beginning. With respect to the GAF scale, patients were considered clinically improved, worsened or unvaried depending on the scoring reported during the retest (a difference in score of at least 10 points was required to define improvement or aggravation, otherwise the patient was considered unvaried). Clinical evolution was statistically studied in relation to other variables: psychiatric diagnosis, timing of intervention, therapeutic compliance, patients' participation, type of intervention.

Psychiatric diagnosis was formulated according to ICD 10 [10] which is the manual of mental health disorders used by clinicians of the Neuropsichiatric Unit of
Padua. Timing of intervention considered a period time less then three months, a period time between three and nine months and a period time longer then nine months. Therapeutic compliance was divided and named in 'adequate' (when the patient started therapy and maintain it in accordance with the therapist), 'discontinuous' (when the patient was partially compliant, missing at least two sessions consecutively, at least once every three months) and 'with interruption' (when the patient dropped out precociously or did not follow the therapeutic indications at all). Patient's participation was evaluated on the basis of patient-therapist interaction verified throughout the analysis of clinical files, reports and minutes of sessions, interviews and equips: the WAI-O (Working Alliance Inventory-Observer version) translated into Italian language [16-18] was used. WAI-O ratings for each patient were assigned by an external clinician requested to read and scrutinize adolescents' medical records. Ratings, ranging from a minimum of 120 to a maximum of 168, were split into three groups: 120-132 (which we named as 'opposition'), 133-145 (which we named as 'ambivalent participation'), 146157 (which we named as 'passive participation') and 158-168 (which we named as 'active participation'). Rating was carried out by a neutral observer during the clinical interviews. The type of intervention was described on the basis of the single treatment or the association of different treatments as explained in the sample section.

Data about patients were collected in an anamnesis schedule, then transferred into a computerised database for computation, which is performed using SSPS version 10 and SAS ${ }^{\circledR}$ package, rel. 9.1.3.

Statistic Analysis: descriptive analysis, performed with SSPS version 10, first included the frequencies distribution of the main variables collected in the study; then since variables were all expressed in a nominal scale, a Chi-squared test was carried out to identify the relationships between therapeutic efficacy and other variables referred to patients. A paired t-test was performed to investigate the differences in YSR's scores before and after the intervention. Multivariate analysis, performed with SAS ${ }^{\circledR}$ package, rel. 9.1.3, consisted in a multivariate logistic regression to identify those variables related to the therapeutic efficacy, while holding the other variables constant in the model. The value of $\mathrm{p}<0.05$ was considered significant.

Among 112 adolescents who were referred in six months time, 100 individuals had been clinically followed for 12 months. They were 66 males and 34 females, aged between 12 and 19 years, affected by emotional and behavioural problems. Their clinical files provided retrospective information about diagnostic and 
therapeutic processes. The sample finally taken into consideration was retrospectively divided into 5 groups under therapeutic treatment:

1) psychological treatment

2) educational treatment

3) psychological and educational integrated treatment

4) psychiatric (pharmacological) and psychological integrated treatment

5) psychological, psychiatric and educational integrated treatment

\section{RESULTS}

Results about frequencies analysis of variables are represented in Tables 1-5.

Multivariate analysis (carried out with the SAS ${ }^{\circledR}$ package, rel. 9.1.3) was performed using a stepwise logistic regression analysis (significance level for entering = 0.15 and significance level for removing $=0.10$ ) to identify variables related to the therapeutic efficacy, which is the dependent dichotomous variable of the study.

Results of Logistic Regression Analysis for patients with an efficient therapy result (cases) compared to patients with a not efficient treatment (controls) are represented in Table 4.

Patients with an adequate therapeutic compliance have a probability 5,762 times higher to present a clinical improvement $(\mathrm{p}$-value $=0.0076)$ compared with patients

Table 1. Observed distribution (frequencies and percentages) by age inter vals and sex.

\begin{tabular}{|c|c|c|c|}
\hline & & Freq & $\%$ \\
\hline \multirow{5}{*}{ Age interv } & $12-14$ yrs & 43 & 43 \\
\hline & $15-17$ yrs & 46 & 46 \\
\hline & & & \\
\hline & (10) & & \\
\hline & Total & 100 & 100 \\
\hline \multirow{3}{*}{ Sex } & Male & 66 & 66 \\
\hline & Female & 34 & 34 \\
\hline & Total & 100 & 100 \\
\hline \multicolumn{4}{|c|}{ Age categories by sex } \\
\hline & Male & Female & Total \\
\hline $12-14$ yrs & $32(74.4)$ & $11(25.6)$ & $43(100.0)$ \\
\hline $15-17$ yrs & 28 (60.9) & $18(39.1)$ & $46(100.0)$ \\
\hline $18-19$ yrs & $6(54.5)$ & $5(45.5)$ & $11(100.0)$ \\
\hline
\end{tabular}

Table 2. Observed distribution (frequencies and percentages) by diagnosis ICD 10 and type of treatment.

\begin{tabular}{|c|c|c|}
\hline & Freq & $\%$ \\
\hline \multicolumn{3}{|l|}{ Diagnosis ICD 10} \\
\hline Psychotic Disorders & 18 & 18 \\
\hline Affective Syndroms & 21 & 21 \\
\hline Neurotic Syndroms & 10 & 10 \\
\hline Personality Disorders & 21 & 21 \\
\hline Soft Mental Retardation & 6 & 6 \\
\hline Behaviour/emotional Disorders & 9 & 9 \\
\hline Eating disorders & 4 & 4 \\
\hline $\begin{array}{l}\text { Comorbility (personality dis. + anxiety } \\
\text { or mood dis.) }\end{array}$ & 11 & 11 \\
\hline Total & 100 & 100 \\
\hline \multicolumn{3}{|l|}{ Type of treatment } \\
\hline Educational Treatment & 16 & 16 \\
\hline Psychological Treatment & 15 & 15 \\
\hline Educational + Psychological Treatment & 19 & 19 \\
\hline Psychological + Psychiatric Treatment & 15 & 15 \\
\hline Educational + Psychiatric Treatment & 7 & 7 \\
\hline $\begin{array}{l}\text { Educational + Psychiatric + Psycho- } \\
\text { logical Treatment }\end{array}$ & 28 & 28 \\
\hline Total & 100 & 100 \\
\hline
\end{tabular}

who are not compliant. A multiprofessional intervention ( $\mathrm{p}$-value $=0.0242)$ and an active participation of the patient during the treatment (p-value $=0,014$ ) is associated with a probability more than four times higher to obtain a clinical improvement. The last variable entered in the model is 'timing of therapy' ( $\mathrm{p}$-value $=0.0163$ ): patients whose therapy lasts less than 3 months present a very lower probability $(\mathrm{OR}=0.062, \mathrm{CI}=0.009-0.439)$ to get clinically better compared with patients whose intervention lasts more than 9 months.

The p-value of likelihood ratio test $<0.0001$ indicates the efficiency of the final model. The percentages of sensitivity and the specificity are respectively $86.2 \%$ and $68.3 \%$.

To analyse the differences in Achenbach's scores (means) before and after the intervention a paired t-test was used. Table 5 shows there was a statistically signifi- 
Table 3. observed distribution (frequencies and percentages) by timing of intervention, patient's participation, therapy eutic Compliance and clinical outcome (GAF).

\begin{tabular}{|c|c|c|}
\hline & Freq & $\%$ \\
\hline \multicolumn{3}{|l|}{ Timing of intervention } \\
\hline$<3$ months & 19 & 19 \\
\hline 3-9 months & 41 & 41 \\
\hline$>9$ months & 40 & 40 \\
\hline Total & 100 & 100 \\
\hline \multicolumn{3}{|l|}{ Patient's participation } \\
\hline Active & 53 & 53 \\
\hline Passive & 17 & 17 \\
\hline Ambivalent & 22 & 22 \\
\hline Total & 100 & 100 \\
\hline \multicolumn{3}{|l|}{ Therapeutic compliance } \\
\hline Adequate & 70 & 70 \\
\hline Discontinuous & 20 & 20 \\
\hline Early interruption & 10 & 10 \\
\hline Total & 100 & 100 \\
\hline Clinical outcome (GAF) & Freq & $\%$ \\
\hline Improved & 58 & 58 \\
\hline Unchanged & 31 & 31 \\
\hline Got worse & 11 & 11 \\
\hline Total & 100 & 100 \\
\hline
\end{tabular}

cant change (p-value < 0.05) in patients' Achenbach's mean scores, most probably due to the treatment efficacy. It is evident, looking at the percentages, that normal scores increased, whereas pathological ones significantly decreased.

Using the chi square test a statistically significant result about the relation between type of association of treatments and clinical evolution was obtained: the patients who got clinically better are those who underwent multiprofessional integrated therapy and in particular association between psychological and educational intervention, (63\%), psychological and psychiatric intervention (71\%) and the three types together (79\%).

\section{DISCUSSION}

The sample is formed by individuals, prevalently boys (66\%), basically aged between 12 to 17 years (Table 1). According to literature which shows as in the childjuvenile sectors of psychiatry, boys outnumber girls until the age of 12-14 years and then girls become the majority [19], in our sample too the gap between genders decreases with age, so that after 17 years of age the percentage of males and females tends to become similar (Table 1). Table 2 shows the diagnosis according to ICD 10 formulated at the end of the psychodiagnostic process. The percentages are quite similar to those of literature about epidemiology of psychiatric disorders in clinic populations of adolescents and young adults [20-22]. The relevant percentage of severe psychopathology as psychosis and personality disorder must be read also within the typology of our service: a second level one which in Italy means a structure functioning in between a outpatients' and inpatients' service, where severe psychiatric diseases are recovered and treated. Tables 2 shows types of intervention and treatments' association: the prevalence of multiprofessional interventions (association of three different therapies in $28 \%$ of cases), besides being indicative again of the complexity of patients' psychopathology, is linked to the general methodology of our Service where an approach to the adolescent that integrates different therapeutic efforts (psychiatric, psychological and educational ones) is preferred when possible to apply. About the timing of interventions, Table 3 shows that most therapies last more than three months (81\%, and $40 \%$ more than nine months). Those patients who underwent therapy for less than three months usually are patients that dropped out. Actually, being the Service one which receives individuals affected by serious psycho-pathology, suggested therapies habitually last 3 months at least. In Table $\mathbf{3}$ it is also shown patient's participation mode in the therapeutic process: active, passive, oppositional or ambivalent. Patient's way to participate during sessions and activities is significant of the relationship with the therapist and working on the therapeutic alliance is very important for a good compliance and a positive outcome [23-25]. Data about therapeutic compliance and clinical outcome (Table 3) show that the most of adolescents (70\%) followed the therapeutic indications adequately and nearly $60 \%$ of adolescents presented a clinical improvement one year later. Results about outcome obtained using the GAF (filled in by the operators) are confirmed by the ones obtained using the YSR (filled in by the patients) (Table 5). Looking at the scores before and after the treatment it can be noticed that there is an improvement for each syndrome scale, with a statistically significant p-value < 
0.05. There are no significant associations between diagnosis and outcome, suggesting that in developmental age a clinical improvement is more dependent on the therapy and the adherence to it, rather than on the specific psychopathology. Particularly, the results about associations between compliance and outcome (patients who undergo to therapy profiting of it) and between therapy timing and outcome (the longer is the therapy, the more probable is the improvement) suggest that the intervention is efficient when the sessions are attended continuously by the adolescent and for a longer time (Table 4). A brief intervention (19\% of adolescents came to the centre for less than 3 months) is strictly connected with the phenomenon of drop out. This phenomenon turns out to be more frequent at the beginning of the treatment, and particularly in the first 3 months which is the period dedicated to knowledge and definition of the therapeutic project. The problem of early interruption is significant for the relation with patients' clinical outcome. Between the adolescents who dropped out and those who took part in the whole therapeutic project, there is a statistically relevant difference in terms of clinical evolution, respectively negative and positive. Generally, it must be pointed out the statisticcally relevant relation between therapeutic compliance and clinical outcome: among patients who are compliant there is a significantly larger rate of adolescents who have showed clinical improvement, compared with the non compliant adolescents. This data, moreover, confirms that patients attending the Neuropsychiatric Unit are affected by a psychological and behavioural disease which needs a moderately long period of time to be worked out. On the basis of this consideration it is possible to interpret the result about the diagnosis (Table 2): such result, actually, shows that most adolescents are affected by serious psychiatric disorders (psychosis 18\%, depression 21\% and personality disorders 21\%). These psychopathological conditions are confirmed by the results of YSR: looking at scores (borderline and clinic ones) before intervention it can be noticed that the most frequent problems were: withdrawal and social problems (69\% and $87 \%)$, anxiety and mood disorders (92\%), attention problems (97\%) (Table 5). Attention problem is probably a symptom of anxious and depressive syndromes rather than a symptom of an ADHD (Attention Deficit and Hyperactivity Disorder). This is supported by the fact that attention problems were reduced after intervention (see YSR scores after intervention, Table 5) even if the treatment was not specifically designed for ADHD and the timing of therapy was not long enough for that kind of disorder.

Our data suggests that an active participation of the adolescent too contributes to the achievement of a positive result. Table 4, actually, shows that an active participation of the patient during the treatment implies a higher probability to obtain a clinical improvement. According to many authors this result confirms that with adolescents, the therapeutic process must be supported by patient's motivation and his/her involvement into therapy dynamics [26-29].

The association between type of intervention and outcome shows that the subjects who got clinically betterare those patients who underwent multiprofessional therapy (Table 4) and, particularly, the associations between psychological and educational intervention, (63\%), psychological and psychiatric intervention (71\%) and the three types together (79\%). It must be pointed out that these three types of multiprofessional intervention have a common element that is the focus on the human relationship: that is the relation between the patient and the clinician/therapist or with the educational professional. Moreover, these types of interventions require an interprofessional team to integrate different therapeutic actions applied to the same patients. Both a multiprofessional intervention (giving a specific answer to the individual and a answer thanks to the intervention of differ-

Table 4. Results of logistic regression analysis for patients with therapy effectiveness (cases) compared to patients without therapy effectiveness (controls).

\begin{tabular}{|c|c|c|c|c|c|}
\hline & $\begin{array}{l}\text { Maximum likelihood } \\
\text { estimate }\end{array}$ & Standard Error & p-value & Odds ratio & $95 \% \mathrm{CI}$ \\
\hline Therapeutic compliance (ref. 'adequate') & 1.751 & 0.656 & 0.0076 & 5.762 & $1.594-20.829$ \\
\hline Type of intervention (ref. 'multiprofessional') & 1.432 & 0.635 & 0.0242 & 4.187 & $1.205-14.544$ \\
\hline $\begin{array}{l}\text { Timing of intervention ('< } 3 \text { months' compated to } \\
\text { '>9 months') }\end{array}$ & -1.483 & 0.617 & 0.0163 & 0.062 & $0.009-0.439$ \\
\hline Patient's participation to the therapy (ref. 'active') & 1.468 & 0.597 & 0.014 & 4.342 & $1.346-14.002$ \\
\hline
\end{tabular}

Likelihood ratio test: $\mathrm{p}<0.0001$. Ref, reference category; CI, confidence intervals. 
Table 5. Distribution of patients by Achenbach's scores before and after the intervention [observed frequencies (\%)] and paired t-test value with corresponding $\mathrm{p}$-value.

\begin{tabular}{|c|c|c|c|c|c|}
\hline & & before (100 patients) & after (94 patients) & paired t-test value & p-value \\
\hline \multirow{3}{*}{ Withdrawal } & normal & $31(31)$ & $66(70.2)$ & \multirow{3}{*}{5.61} & \multirow{3}{*}{$<0.0001$} \\
\hline & borderline & $21(21)$ & $19(20.2)$ & & \\
\hline & clinic & $48(48)$ & $9(9.6)$ & & \\
\hline \multirow{3}{*}{ Somatic complaints } & normal & $41(41)$ & $67(71.3)$ & \multirow{3}{*}{5.03} & \multirow{3}{*}{$<0.0001$} \\
\hline & borderline & $40(40)$ & 25 (26.6) & & \\
\hline & clinic & $19(19)$ & $2(2.1)$ & & \\
\hline \multirow{3}{*}{ Anxious-depressive problems } & normal & $8(8)$ & $41(43.6)$ & \multirow{3}{*}{9.79} & \multirow{3}{*}{$<0.0001$} \\
\hline & borderline & $31(31)$ & $50(53.2)$ & & \\
\hline & clinic & $61(61)$ & $3(3.2)$ & & \\
\hline \multirow{3}{*}{ Social problems } & normal & $13(13)$ & $45(47.9)$ & \multirow{3}{*}{6.43} & \multirow{3}{*}{$<0.0001$} \\
\hline & borderline & $41(41)$ & $41(43.6)$ & & \\
\hline & clinic & $46(46)$ & $8(8.5)$ & & \\
\hline \multirow{3}{*}{ Thought problems } & normal & $40(40)$ & $64(68.1)$ & \multirow{3}{*}{3.54} & \multirow{3}{*}{$<0.001$} \\
\hline & borderline & $35(35)$ & $23(24.5)$ & & \\
\hline & clinic & $25(25)$ & $7(7.4)$ & & \\
\hline \multirow{3}{*}{ Problems of Attention } & normal & $30(30)$ & $65(69.1)$ & \multirow{3}{*}{6.45} & \multirow{3}{*}{$<0.0001$} \\
\hline & borderline & $46(46)$ & 27 (28.7) & & \\
\hline & clinic & $24(24)$ & $2(2.1)$ & & \\
\hline \multirow{3}{*}{ Delinquent behaviour } & normal & $80(80)$ & $84(89.4)$ & \multirow{3}{*}{2.49} & \multirow{3}{*}{$<0.05$} \\
\hline & borderline & $14(14)$ & $9(9.6)$ & & \\
\hline & clinic & $6(6)$ & $1(1.1)$ & & \\
\hline \multirow{3}{*}{ Aggressive behaviour } & normal & $54(54)$ & 75 (79.8) & \multirow{3}{*}{4.58} & \multirow{3}{*}{$<0.0001$} \\
\hline & borderline & $27(27)$ & $17(18.1)$ & & \\
\hline & clinic & $19(19)$ & $2(2.1)$ & & \\
\hline
\end{tabular}

ent professionals) and a shared methodology with the possibility of verifying the work done on the individual within a group, contribute to a positive outcome [30,31]. According to that, many studies have just tested the efficiency of multimodal interventions on different psychopathologies such as ADHD, anxiety disorders, suicidal behaviours, conduct disorders, psychosis etc. [32-35].

\section{CONCLUSIONS}

This study, with the limitation of being a retrospective research, confirms the major efficacy of a multiprofessional integrated approach to the adolescent's psychopathology in comparison with approaches based on a single therapeutic intervention.

A rigid separation among approaches could actually make the operator run the risk of getting a deformed vision of patient's real needs. This approach does not consider the patient as a complex whole and could easily lead to partial and inefficient interventions.

In order to obtain a positive clinical outcome in the treatment of young patients affected by psychiatric dis- 
ease, it is essential to organize services for adolescents trying to stimulate and support team work, so as to assure a multiprofessional intervention.

\section{REFERENCES}

[1] Bachmann, M., Bachmann, C., Rief, W. and Mattejat, F. (2008) Efficacy of psychiatric and psychotherapeutic interventions in children and adolescents with psychiatric disorders-A systematic evaluation of meta-analyses and reviews. Part II: ADHD and conduct disorders. Z Kinder Jugendpsychiatr Psychother, 36(5), 321-333.

[2] Bachmann, M., Bachmann, C., Rief, W. and Mattejat, F. (2008) Efficacy of psychiatric and psychotherapeutic interventions in children and adolescents with psychiatric disorders-a systematic evaluation of meta-analyses and reviews. Part I: Anxiety disorders and depressive disorders. Z Kinder Jugendpsychiatr Psychother, 36(5), 309320.

[3] Velligan, D.I., Draper, M., Stutes, D., Maples, N., Mintz, J., Tai, S. and Turkington, D. (2009) Multimodal Cognitive Therapy: Combining Treatments That Bypass Cognitive Deficits and Deal With Reasoning and Appraisal Biases. Schizophrenia Bulletin, 35(5), 884-893.

[4] MTA Cooperative Group National Institute of Mental Health (2004) Multimodal Treatment Study of ADHD Follow-up: 24-Month Outcomes of Treatment Strategies for Attention-Deficit/Hyperactivity Disorder. Pediatrics, 113(4), 754-761.

[5] Connor, D.F., Carlson, G.A., Chang, K.D., Daniolos, P.T., Ferziger, R., Findling, R.L., Hutchinson, J.G., Malone, R.P., Halperin, J.M., Plattner, B., Post, R.M., Reynolds, D.L., Rogers, K.M., Saxena, K., Steiner, H., Stanford/Howard/AACAP Workgroup on Juvenile Impulsivity and Aggression (2006) Juvenile maladaptive aggression: a review of prevention, treatment, and service configuration and a proposed research agenda. Journal of Clinical Psychiatry, 67(5), 808-820.

[6] Masi, G., Milone, A., Manfredi, A., Pari, C., Paziente, A. and Millepiedi, S. (2008) Conduct disorder in referred children and adolescents: Clinical and therapeutic issues. Comprehensive Psychiatry, 49(2), 146-153.

[7] Herpertz-Dahlmann, B. and Salbach-Andrae, H. (2009) Over-view of treatment modalities in adolescent anorexia nervosa. Child and Adolescent Psychiatric Clinics of North America, 18(1), 131-145.

[8] Steiner, H. and Remsing, L. (2007) Work Group on Quality Issues Practice parameter for the assessment and treatment of children and adolescents with oppositional defiant disorder. Journal of the American Academy of Child and Adolescent Psychiatry, 46(1), 126-141.

[9] Nützel, J., Schmid, M., Goldbeck, L., Fegert, J.M. (2005) Psychiatric support for children and adolescents in residential care in a German sample. Praxis der Kinderpsychologie und Kinderpsychiatrie, 54(8), 627-644.

[10] World Health Organization (1992) The ICD-10 Classification of Mental and Behavioural Disorders: Clinical Descriptions and Diagnostic Guidelines. WHO, Geneva.

[11] American Psychiatric Association (1994) Diagnostic and Statistical Manual of Mental Disorders, Axis V. American
Psychiatric Association, Washington, D.C.

[12] Startup, M., Jackson, M.C., Bendix, S. (2002) The concurrent validity of the Global Assessment of Functioning (GAF). British Journal of Clinical Psychology, 41(4), 417-422.

[13] Achenbach, T.M., Rescorla, L.A. (2001) Manual for the ASEBA School Age-Forms \& Profiles. University of Vermont, Research Center for Children, Burlington.

[14] Ivanova, M.Y., Achenbach, T.M., Rescorla, L.A., Dumenci, L., Almqvist, F., Bilenberg, N., Bird, H., Broberg, A.G., Dobrean, A., Döpfner, M., Erol, N., Forns, M., Hannesdottir, H., Kanbayashi, Y., Lambert, M.C., Leung, P., Minaei, A., Mulatu, M.S., Novik, T., Oh, K.J., Roussos, A., Sawyer, M., Simsek, Z., Steinhausen, H.C., Weintraub, S., Winkler Metzke, C., Wolanczyk, T., Zilber, N., Zukauskiene, R. and Verhulst, F.C. (2007) The generalizability of the Youth Self-Report syndrome structure in 23 societies. Journal of Consulting and Clinical Psychology, 75(5), 729-738.

[15] Ivanova, M.Y., Dobrean, A., Dopfner, M., Erol, N., Fombonne, E., Fonseca, A.C., Frigerio, A., Grietens, H., Hannesdottir, H., Kanbayashi, Y., Lambert, M., Achenrbach, T.M., Larsson, B., Leung, P., Liu, X., Minaei, A., Mulatu, M.S., Novik, T.S., Oh, K.J., Roussos, A., Sawyer, M., Simsek, Z., Dumenci, L., Steinhausen, H.C., Metzke, C.W., Wolanczyk, T., Yang, H.J., Zilber, N., Zukauskiene, R., Verhulst, F.C., Rescorla, L.A., Alm-qvist, F., Weintraub, S., Bilenberg, N., Bird, H. and Chen, W.J. (2007) Testing the 8 syndrome structure of the CBCL in 30 societies. Journal of Clinical Child and Adolescent Psychology, 36(3), 405-417.

[16] Horvath, A.O. and Greenberg, L.S. (1989) Development and validation of the working alliance inventory. Journal of Counseling Psychology, 36(2), 223-233.

[17] Di Giuseppe, R., Linscott, J. and Jilton, R. (1996) Developing the therapeutic alliance in children-adolescent psychotherapy. Applied \& Preventive Psychology, 5(2), 85-100.

[18] Lingiardi, V. (2002) L'alleanza terapeutica. Teoria, clinica, ricerca. Cortina Raffaello, Milano.

[19] Cohen, P., Cohen, J., Kasen, S., Velez, C.N., Hartmark, C., Johnson, J., Rojas, M., Brook, J. and Streuning, E.L. (1993) An epidemiological study of disorders in late childhood and adolescence-I. Age- and gender-specific prevalence. Journal of Child Psychology and Psychiatry, 34(6), 851-867.

[20] Costello, E.J., Foley, D. and Angold, A. (2006) 10-Year Research Update Review: The Epidemiology of Child and Adolescent Psychiatric Disorders: II. Developmental Epidemiology. Journal of the American Academy of Child \& Adolescent Psychiatry, 45(1), 8-25.

[21] Gabbard, G.O. (2000) Psychodynamic Psychiatry in Clinical Practice, 3rd Edition. American Psychiatric Press, Washington, D.C.

[22] Donald, W., Spady, M.D., Donald, P., Schopflocher, Lawrence, W., Svenson, B., Angus and H., Thompson. (2001) Prevalence of mental disorders in children living in Alberta, Canada, as determined from physician billing data. Archives of Pediatrics \& Adolescent Medicine, 155, 1153-1159.

[23] Horvath, A.O. and Symonds, B.D. (1991) Relation be- 
tween working alliance and outcome in psychotherapy: A meta-analysis. Journal of Counselling Psychology, 38(2), 139-149.

[24] Luborsky, L. (2000) A pattern-setting therapeutic alliance study revisited: helping alliances in psychotherapy. Psychotherapy Research, 10, 17-29.

[25] Martin, D.J., Garske, J.P., Davis, M.K. (2000) Relation of the therapeutic alliance with outcome and other variables: A meta-analytic review. Journal of Consulting and Clinical Psychology, 68(3), 438-450.

[26] Horvath, A.O. and Luborsky, L. (1993) The role of therapeutic alliance in psychotherapy. Journal of Consulting and Clinical Psychology, 61(4), 561-573.

[27] Marcelli, D. and Braconnier, A. (1995) Adolescence et Psychopathologie. Masson, Paris.

[28] Laufer, M. (1997) Adolescent Breakdown and Beyond. Karnak Books, London.

[29] Hintikka, U., Laukkanen, E., Marttunen, M. and Lehtonen, J. (2006) Good working alliance and psychotherapy are associated with positive changes in cognitive perfor- mance among adolescent psychiatric inpatients. Bulletin of the Menninger Clinic, 70, 316-335.

[30] Wachtel, P.L. (1977) Psychoanalysis and behaviour therapy: Toward an integration. Guilford Press, New York.

[31] Kaneklin, C. and Orsenigo, A. (1992) Il lavoro di Comunità. Nuova Italia Scientifica, Roma.

[32] Rea, M., Braccini, L., Laviola, G., Ferri, R. (2006) ADHD and multimodal intervention. Annali dell' Istituto Superiore di Sanità, 42(2), 231-245.

[33] Russell, P.S., Raj, S.E., John, J.K. (1998) Multimodal intervention for selective mutism in mentally retarded children. Journal of the American Academy of Child and Adolescent Psychiatry, 37(9), 903-904.

[34] Henggeler, S.W., Schoenwald, S.K., Borduin, C.M., Rowland, M.D. and Cunningham, P.B. (1998) Multi-systemic treatment of antisocial behaviour in children and adolescents. Guilford Press, New York.

[35] Clark, A.F. (2001) Proposed treatment for adolescent psychosis. Schizophrenia and schizophrenia-like psychoses. Advances in Psychiatric Treatment, 7, 16-23. 